\title{
Preparation of red elemental nanoselenium by Arabic gum template method
}

\author{
Qingbing Guo ${ }^{1}$, Xuegui Lin ${ }^{1}$, Ming $\mathrm{He}^{1}$, Guojie $\mathrm{Wu}^{1 *}$ \\ ${ }^{1}$ College of Chemistry and Chemical Engineering, Zhongkai University of Agriculture and Engineering, Guangzhou, PRC
}

\begin{abstract}
Red elemental nanoselenium was prepared by reducing sodium selenite with ascorbic acid using Arabic resin as template in this study. The factors effecting on the particle size change of nanoselenium such as reaction time, reactant concentration, template mass fraction and reaction temperature were studied. The orthogonal experiment $\mathrm{L} 9\left(3^{4}\right)$ was designed to determine the optimal process conditions. The elemental nanoselenium was characterized by IR and particle size analyzer. The results showed that the stable red elemental selenium with nanometer scale was prepared.
\end{abstract}

\section{Introduction}

Red selenium has not only the general physicochemical properties, but also has more excellent biological activity and lower toxicity than inorganic selenium and organic selenium. It has been widely used in animal nutrition, medical and health care etc ${ }^{[1,2]}$. The preparation of red selenium was usually to reduce selenium salt or selenium compounds to form selenium monomer by reducing agent and kept the particle size at nanometer in various ways before it clustered into clusters. Template method is a method to generate the nanoparticles with uniform dispersion and proper particle size in the pore size of the carrier by using the appropriate compound as the carrier. Because of the porous nature of template material, the pore size is about $1-100 \mathrm{~nm}$, thus the size of the product generated in the template can be controlled in the nano scale $^{[3]}$. In this study, the red nanoselenium was synthesized by using Arabic resin as template, characterized by IR and particle size analyzer, and the factors affecting the particle size were studied.

\section{Experiment}

\subsection{Materials and Instruments}

Sodium selenite was provided by Shandong West Asia Chemical Industry Co., Ltd., L(+)-ascorbic acid $(\mathrm{Vc})$ was purchased from Guangdong Guanghua Technology Co., Ltd., and Arabic gum was supplied by Aladdin Reagent Co., Ltd.

Uv2600 ultraviolet visible spectrophotometer (Shanghai Tianmei Scientific Instrument Co., Ltd.), Iraffinity-1s Fourier transform infrared spectrometer was (Shimadzu company), 90Plus Zeta Particle size and Zeta potential analyzer (Brooke Haiwen Instruments, USA).

\subsection{Test methods}

Sodium selenite solution and the Arabic gum solution were mixed in the test tube, shaken well, and then Vc solution, a newly prepared reducing agent was added. After mixing well, ionic water was added to make the volume of the reaction system reach $10 \mathrm{~mL}$. After shaking, the reaction was continued for some time.

The dual wavelength method was used to measure the change of the size of the nanoselenium and the absorbance was measured by ultraviolet visible spectrophotometer.

After ultrasonic treatment for 5 minutes in the ultrasonic cleaner and standing at $25^{\circ} \mathrm{C}$, the product was dialyzed, the particle size was measured by laser granule size instrument and the structure of product was analyzed by IR spectrometer.

\section{Results and discussion}

\subsection{UV absorption spectra of nanoselenium}

The absorption spectrum obtained by scanning the UV visible spectrophotometer at $350-600 \mathrm{~nm}$ wavelength after the reaction system $\left(0.005 \mathrm{~mol} / 1 \mathrm{Na}_{2} \mathrm{SeO}_{3}\right.$ reacts with $0.015 \mathrm{~mol} / 1 \mathrm{Vc}$ in $0.5 \%$ gum of Arabic gum with mass fraction of $0.015 \mathrm{~mol} / 1 \mathrm{Vc}$ at $25{ }^{\circ} \mathrm{C}$ for $25 \mathrm{~min}$ ) was shown in Fig. 1. There is a clear absorption peak in $360-370 \mathrm{~nm}$. Because the red shift of the absorption peak is linear with the concentration of the product, it indicates that the absorption peak is caused by the formation of selenium in red monomer. In the range of $375-380 \mathrm{~nm}$, the absorbance curve tends to be flat after a red shift of the absorption peak, indicating that a large amount of red selenium was produced, and the solution was in a stable colloid state. The absorption peak intensity at $590 \mathrm{~nm}$ was enhanced and the red shift was further increased, indicating that the red

\footnotetext{
* Corresponding author: gjwu@gdut.edu.cn
} 
selenium may agglomerate and the colloid state was unstable. To reduce the absorption of background, 410nm and 490nm were selected as the determination wavelength of nanoselenium solution, and the ratio of absorbance A450/A530 was used as the basis to characterize the particle size change of the product. According to the dual wavelength method, when the absorbance ratio A450/A530 is constant, the colloidal particle size is stable, and the larger the ratio is, the smaller the particle size is, and the more stable the morphology is ${ }^{[4]}$. The wavelength of $450 \mathrm{~nm}$ and $530 \mathrm{~nm}$ were selected to determine the red selenium solution to facilitate the determination. The absorbance ratio (A450/A530) at these two wavelengths was regarded as the judgment basis for characterizing the change of the particle size of the red selenium.

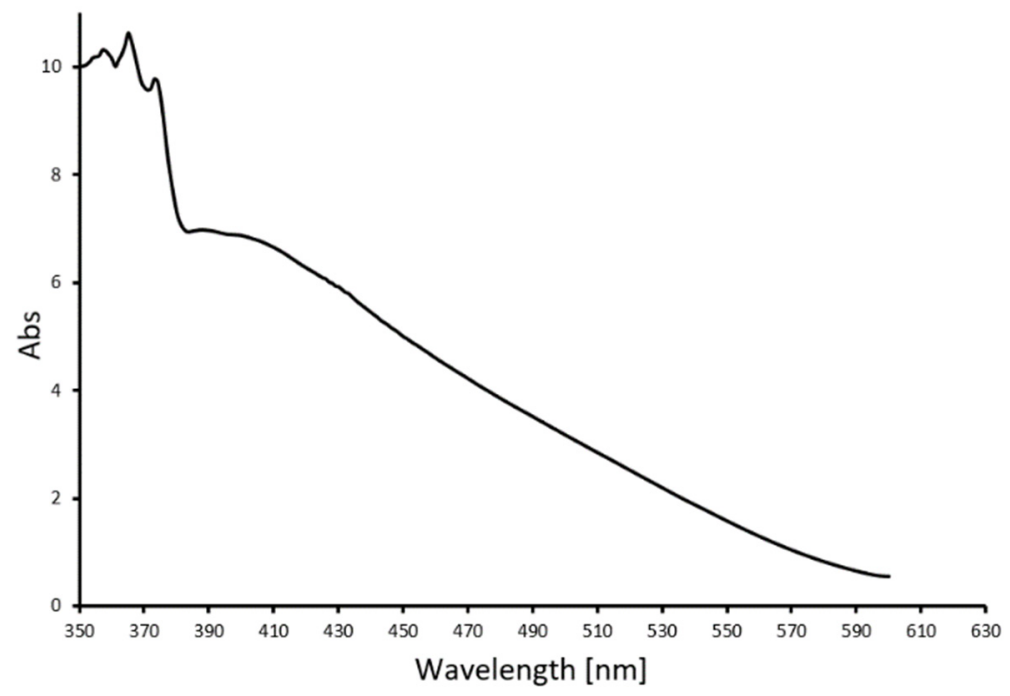

Fig. 1 Absorption spectrum of Arabic gum template

\subsection{Effect of reaction time on nanoselenium}

The curve of absorbance changes of $\mathrm{Na}_{2} \mathrm{SeO}_{3}$ concentration of $0.005 \mathrm{~mol} / 1,0.5 \%$ of gum arabic and $0.02 \mathrm{~mol} / \mathrm{l}$ of $\mathrm{Vc}$ concentration in the reaction system at 25 ${ }^{\circ} \mathrm{C}$ at room temperature was exhibited in Fig. 2. The absorbance of the reaction solution increased with the increase of reaction time, and then gradually increased, and finally remained unchanged, while the absorbance ratio A450/A530 was maintained at 2.24. It can be concluded that the red selenium produced by the reaction was in stable state and the size of the particle size remained unchanged.

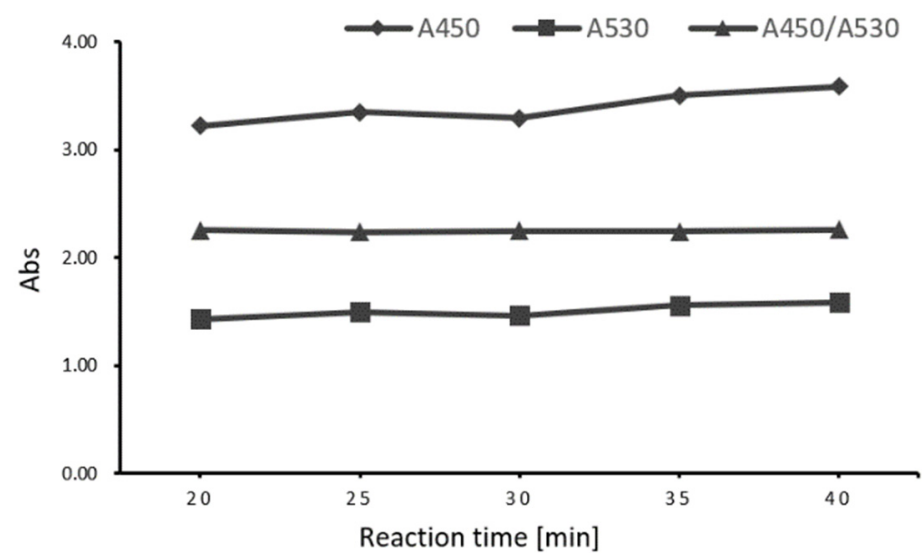

Fig. 2 Effect on the ration of A450/A530 of Reaction time

\subsection{Effect of sodium selenite concentration on nanoselenium}

Fig. 3 is the absorbance curve of the reaction system in which the mass fraction of Arabic gum was $0.5 \%$, the concentration of $\mathrm{Vc}$ was $0.02 \mathrm{~mol} / 1$, the concentration of $\mathrm{Na}_{2} \mathrm{SeO}_{3}$ was changed, and the reaction time was $30 \mathrm{~min}$ at $25^{\circ} \mathrm{C}$. With the increase of $\mathrm{Na}_{2} \mathrm{SeO}_{3}$ concentration, the absorbance of the reaction solution first increased gradually, and finally tended to remain unchanged, while the absorbance ratio A450/A530 maintained at 2.25. The results showed that the reaction reached equilibrium, the red elemental selenium reached stable state, and the particle size remained unchanged. 


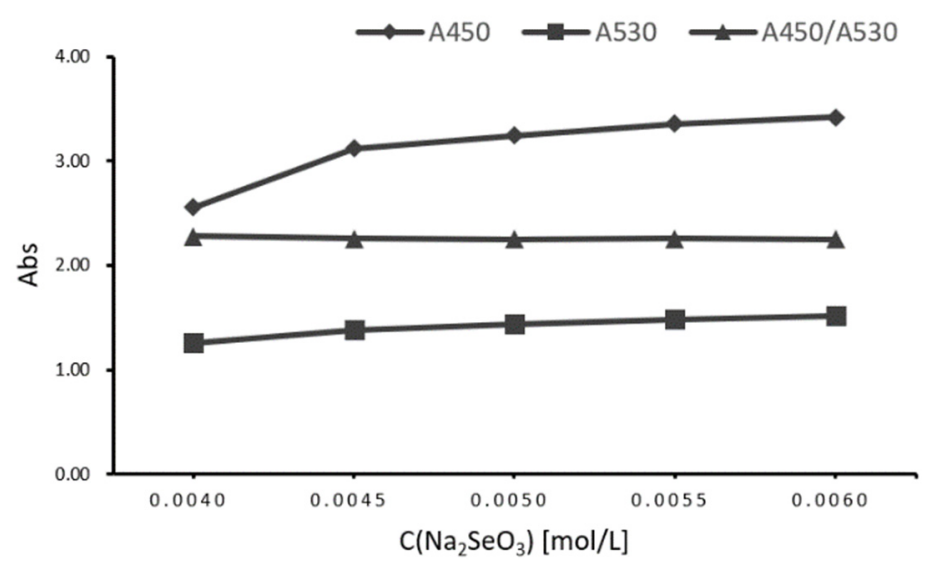

Fig. 3 Effect on the ration of A450/A530 of sodium selenite concentration

\subsection{Effect of ascorbic acid concentration on nanoselenium}

Fig. 4 is the absorbance curve of the reaction system in which the mass fraction of gum Arabic was kept at $0.5 \%$, the concentration of $\mathrm{Na}_{2} \mathrm{SeO}_{3}$ was $0.005 \mathrm{~mol} / \mathrm{l}$, the concentration of $\mathrm{Vc}$ was changed, and the reaction time was $30 \mathrm{~min}$ at $25^{\circ} \mathrm{C}$. With the increase of $\mathrm{Vc}$ concentration, the absorbance of the reaction solution first increased gradually, and finally remained unchanged, while the absorbance ratio A450/A530 maintained at 2. The results showed that the reaction reached equilibrium, the red elemental selenium reached a stable state, and the particle size remained unchanged. In the reaction system, the ratio of $\mathrm{Vc}$ to sodium selenite $\left(\mathrm{Na}_{2} \mathrm{SeO}_{3}\right)$ was $2: 1$. In this study, Vc was excessive, which was conducive to the complete reaction of sodium selenite and the stability of red elemental selenium.

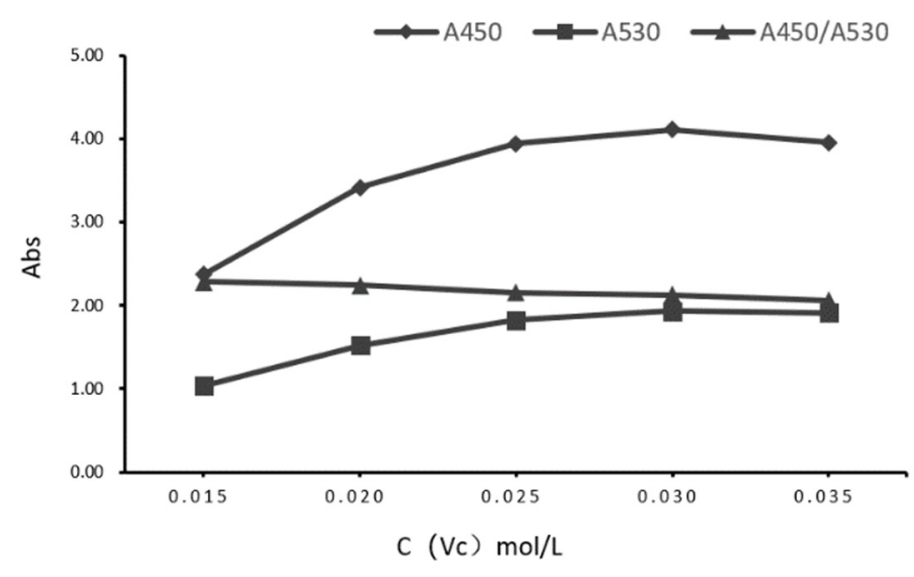

Fig. 4 Effect on the ration of A450/A530 of ascorbic acid concentration

\subsection{Effect of Arabic gum content on nanoselenium}

Fig. 5 showes the absorbance curve of the reaction system in which the concentration of $\mathrm{Na}_{2} \mathrm{SeO}_{3}$ was $0.005 \mathrm{~mol} / 1$, the concentration of $\mathrm{Vc}$ was $0.02 \mathrm{~mol} / 1$, the mass fraction of Arabic gum was changed, and the reaction time was $30 \mathrm{~min}$ at $25^{\circ} \mathrm{C}$. With the increase of Arabic gum content, the absorbance of the reaction solution increased gradually firstly, and finally remained unchanged, with little change on the whole study range. At the same time, the absorbance ratio A450/A530 was maintained at about 2.25. The results showed that the reaction reached equilibrium, the red elemental selenium reached a stable state, and the particle size remained unchanged. In this study, Arabic gum was used as a template. During the reaction process, the solution gradually changed from transparent to orange yellow, and then gradually deepened to orange red. In the whole process, the colour changed slowly, indicating that Arabic gum can slow down the formation rate of red elemental selenium and prevent the agglomeration of elemental selenium particles. It is beneficial to control the particle size of red elemental selenium. 


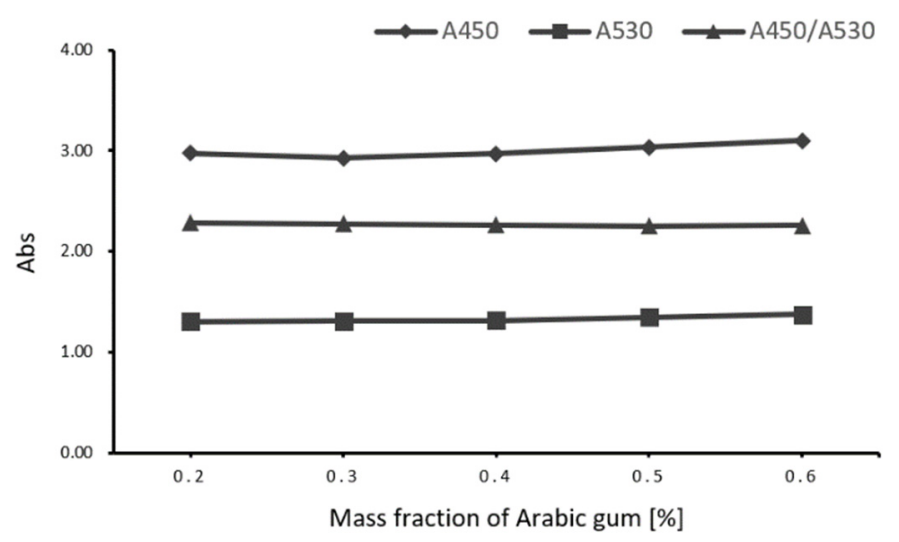

Fig. 5 Effect on the ration of A450/A530 of gum arabic mass fraction

\subsection{Orthogonal test}

Based on the single factor test, reaction time (A, min), the concentration of sodium selenite $(\mathrm{B}, \mathrm{mol} / \mathrm{L})$, mass fraction of gum Arabic $(\mathrm{C}, \%)$ and the concentration of ascorbic acid $(\mathrm{D}, \mathrm{mol} / \mathrm{L})$ were used independent variables, and the absorbance ratio A450/A530 was used as the optimization index. The reaction time, the concentration of sodium selenite, mass fraction of gum Arabic and the concentration of ascorbic acid were optimized by 4 factors and 3 levels orthogonal test $\mathrm{L} 9\left(3^{4}\right)$ to synthesize the red elemental selenoprotein, and the test results and visual analysis are shown in Tab. 1.
The influence degree of all factors in orthogonal test is ascorbic acid concentration(D) $>$ reaction time(A) $>$ sodium selenite concentration(B) $>$ gum content(C). It is known that the ideal experimental scheme is $A_{1} B_{3} C_{2} D_{1}$. It is easy to see that when the concentration of sodium selenite in the reaction system is $0.005 \mathrm{~mol} / 1$ and $0.006 \mathrm{~mol} / \mathrm{L}$, the difference between the absorbance ratio is very small, indicating that the particle size of each other is basically the same. Considering the economic effect, $0.005 \mathrm{~mol} / \mathrm{L}$ of sodium selenite was chosen as the design scheme of sodium selenite concentration. The design of red elemental nanoselenium prepared by the gum template is $0.005 \mathrm{~mol} / 1$ sodium selenite, $0.5 \%$ of the gum, $0.015 \mathrm{~mol} / 1$ of $\mathrm{Vc}$, and reacts for $25 \mathrm{~min}$ at $25^{\circ} \mathrm{C}$.

Tab. 1 Design and visual analysis of $\mathrm{L} 9\left(3^{4}\right)$ orthogonal test

\begin{tabular}{cccccc}
\hline No. & $\mathrm{A}$ & $\mathrm{B}$ & $\mathrm{C}$ & $\mathrm{D}$ & Index \\
\hline 1 & $1(25)$ & $1(0.005)$ & $1(0.4)$ & $1(0.015)$ & 2.2823 \\
2 & 1 & $2(0.0055)$ & $2(0.5)$ & $2(0.020)$ & 2.2521 \\
3 & 1 & $3(0.006)$ & $3(0.6)$ & $3(0.025)$ & 2.1602 \\
4 & $2(30)$ & 1 & 2 & 3 & 2.1577 \\
5 & 2 & 2 & 3 & 1 & 2.2527 \\
6 & 2 & 3 & 1 & 2 & 2.2568 \\
7 & $3(35)$ & 1 & 3 & 2 & 2.2174 \\
8 & 3 & 2 & 1 & 3 & 2.0468 \\
9 & 3 & 3 & 2 & 1 & 2.2673 \\
$\mathrm{k} 1$ & 2.2315 & 2.2191 & 2.1953 & 2.2674 & 2.2421 \\
$\mathrm{k} 2$ & 2.2224 & 2.1839 & 2.2257 & 2.1216 & \\
$\mathrm{k} 3$ & 2.1772 & 2.2281 & 2.2101 & 0.1458 & \\
$\mathrm{R}$ & 0.0543 & 0.0442 & 0.0304 & & \\
\hline
\end{tabular}

\subsection{Infrared spectrum analysis of nanoselenium}

The IR spectrum of the dialyzed product determined by Fourier transform infrared spectrometer was exhibited in
Fig. 6. The absorption peak at $3618 \mathrm{~cm}^{-1}$ is caused by $\mathrm{O}-\mathrm{H}$ stretching vibration of Arabic gum, the absorption peak at $1643 \mathrm{~cm}^{-1}$ is caused by $\mathrm{C}=\mathrm{C}$ stretching vibration of Arabic gum, and the absorption peak from $1512 \mathrm{~cm}^{-1}$ to $1550 \mathrm{~cm}^{-1}$ is caused by red elemental selenium. The results showed that selenium was stable in Arabic gum template. 


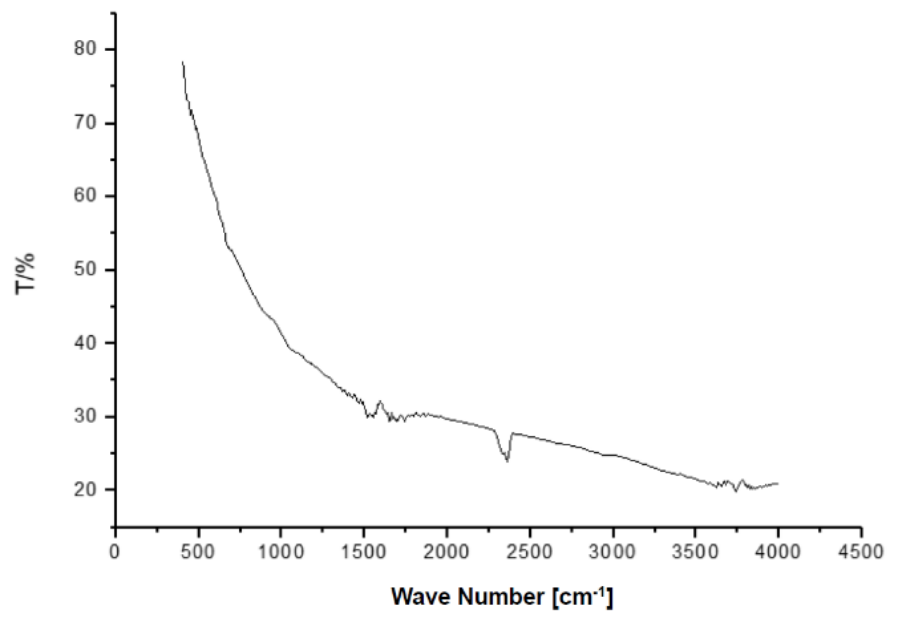

Fig. 6 IR spectrum of nanoselenium

The particle size distribution of nano selenium is shown in Figure 7 and the inside picture is the appearance of product. The average size of selenium is $81 \mathrm{~nm}$, and the product presents a red appearance. The selenium was prepared by ultrasonic treatment in ultrasonic cleaner for $5 \mathrm{~min}$ and room temperature standing at $25^{\circ} \mathrm{C}$ and stored at $25^{\circ} \mathrm{C}$. The results showed that the colour of the solution was not changed obviously, while the samples treated by ultrasonic can be stored for 2 months. The results showed that the colour of the red selenium treated by ultrasonic was more stable and the particles were distributed uniformly and not easy to agglomerate.

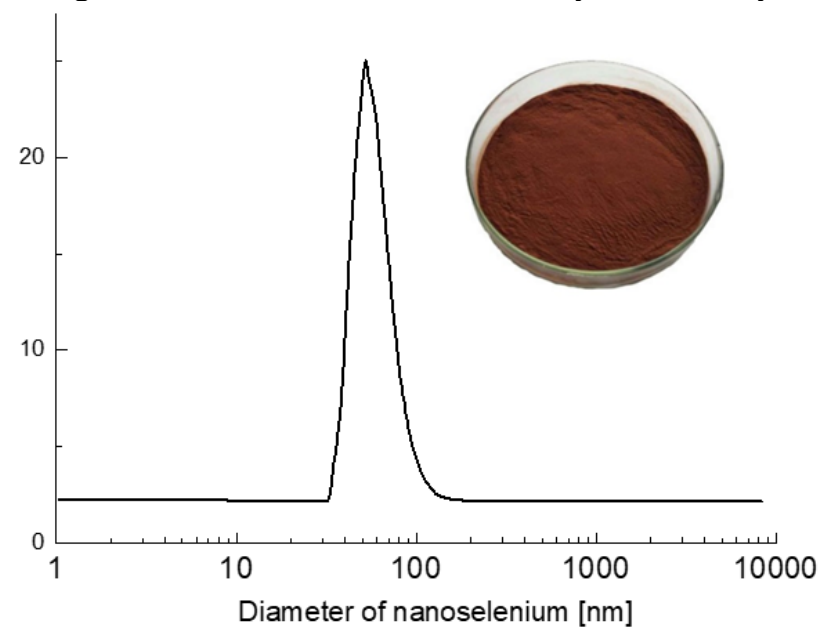

Fig. 7 The diameter of nanoselenium (The inside picture is the appearance of product)

\section{Conclusion}

Red elemental nanoselenium was prepared by reducing sodium selenite with ascorbic acid using Arabic resin as template and the factors effecting on the particle size change of nanoselenium were studied. Based on the orthogonal test, the influence degree of all factors in orthogonal test is ascorbic acid concentration $>$ reaction time $>$ sodium selenite concentration $>$ gum content. When the concentration of sodium selenite is $0.005 \mathrm{~mol} / \mathrm{L}$, the mass fraction of Arabic gum is $0.5 \%$, the concentration of ascorbic acid is $0.015 \mathrm{~mol} / \mathrm{L}$, the reaction temperature is $25{ }^{\circ} \mathrm{C}$, and the reaction time is $25 \mathrm{~min}$, and the stable red elemental nanoselenium with particle size of $81 \mathrm{~nm}$ can be produced.

\section{Acknowledgments}

This work was supported by the Guangzhou Science and
Technology Planning Project (No. 201704020055).

\section{References}

1. Wu G, Lin X, Liu Y, et al. Biosynthesis of Red Elemental Selenium Protein [J]. E3S Web of Conferences, 2019, 131(01011): 1-5.

2. Shi Min, Qiao Yudan. Anti-tumour effect of Nano Seleniums and its mechanism for mice with transplanted tumour $\mathrm{H} 22[\mathrm{~J}]$. Journal of Jiangxi University of TCM, 2008, 20(1): 61-63.

3. Li Zhilin, Hua Pengmin. Preparation of nano-sized selenium by sodium dodecylsulfate template method [J]. Inorganic Chemicals Industry, 2009, (07): 32-34.

4. Zhao Shengnan. Preparation and Bioactivity of Different Sizes Nano-Selenium [D]; Jiamusi University, 2019. 